Rhode Island College

Digital Commons @ RIC

$5-8-2021$

\title{
Nurse's Knowledge of Early Ambulation of the Post Operative Patient and Complication Prevention: A Quality Improvement Project
}

Meghan K. Carides

Follow this and additional works at: https://digitalcommons.ric.edu/etd

Part of the Nursing Commons

\section{Recommended Citation}

Carides, Meghan K., "Nurse's Knowledge of Early Ambulation of the Post Operative Patient and Complication Prevention: A Quality Improvement Project" (2021). Master's Theses, Dissertations, Graduate Research and Major Papers Overview. 375.

https://digitalcommons.ric.edu/etd/375

This Major Paper is brought to you for free and open access by the Master's Theses, Dissertations, Graduate Research and Major Papers at Digital Commons @ RIC. It has been accepted for inclusion in Master's Theses, Dissertations, Graduate Research and Major Papers Overview by an authorized administrator of Digital Commons @ RIC. For more information, please contact digitalcommons@ric.edu. 
Nurse's Knowledge of Early Ambulation of the Post Operative Patient and Complication

Prevention: A Quality

Improvement Project

by

Meghan K. Carides

A Major Paper Submitted in Partial Fulfillment

of the Requirements for the Degree of

Master of Science in Nursing

in

The School of Nursing

Rhode Island College

2021 


\begin{abstract}
Ambulation is the single most important nursing intervention in the prevention of postoperative complications. It is also a key component in maintaining optimal patient outcomes. Current literature has revealed that when ambulation is initiated early there is a marked decrease in pain, length of hospital admission, and overall complication rates. However, even with this depth of evidence early postoperative ambulation on the two surgical units at a teaching hospital in Rhode Island, patient ambulation continues to be inconsistent. The purpose of this quality improvement project is to improve nursing knowledge regarding early ambulation after surgery for the prevention of post-operative complications. This project utilized a pretest, educational in-service intervention, and posttest design. Seventeen out of a possible 22 surgical nurses participated in this project $(\mathrm{N}=17,77 \%)$. The educational in-service sessions combined information from an extensive literature review in the form of a 10-minute Power Point presentation. Pre and post tests were made up of 5 knowledge-based and 5 opinion-based questions. The mean scores for the pretest were $74 \%$ while the mean scores for the posttest were $95.2 \%$. There was a $35 \%$ increase in overall scores following the educational intervention. APRNs play a pivotal role in establishing and implementing educational programs. This project aimed to recognize a need for ongoing education about postoperative ambulation for the surgical unit nurses. Educational programs about postoperative ambulation and complication prevention should be routinely incorporated in future trainings to ensure improved nursing knowledge and patient outcomes.
\end{abstract}




\section{Table of Contents}

Background/Statement of the Problem ................................................................ 1

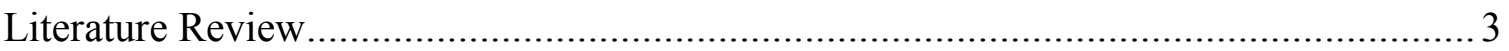

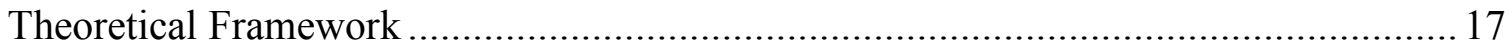

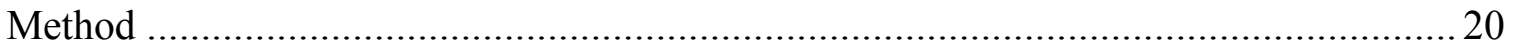

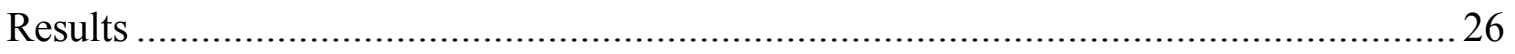

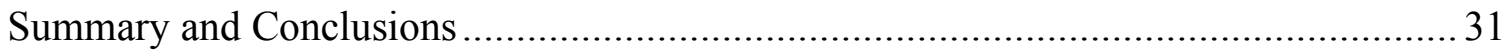

Recommendations and Implications for Advanced Nursing Practice .......................... 35

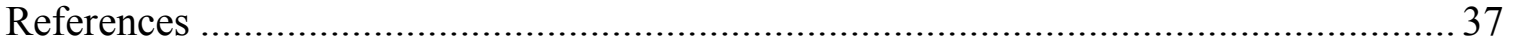

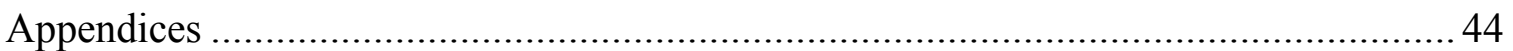


Nurse's Knowledge of Early Ambulation of the Post-Operative Patient and Complication Prevention: A Quality Improvement Project

\section{Background/Statement of the Problem}

Ambulating after a surgical procedure plays a substantial part in the prevention of complications post-operatively. Ambulation is a fundamental component of nursing today however, it was not commonly practiced until 1950 's. Dr. Leithauser, a Detroit based surgeon remarked on ambulation stating "Ten years ago, early ambulation was considered a crack-pot idea. Today it is recognized and is rapidly approaching a must procedure following a surgical operation (Leithauser, 1949, p. 368).” Today, early postoperative ambulation has become an essential component of postsurgical care and is an important nursing intervention. (Kibler et al., 2012).

Immobility is a clinical condition in which an individual is not able to feely move or is limited for therapeutic purposes. Complications of immobility not only influence a patient's health state and quality of life, but also carry a significant cost for healthcare systems (Zhen et al., 2018). Being immobile for any given period of time, especially after surgery, can start a cascade of events that place a patient in harm's way. Problems such as increased pain, deep vein thrombosis (DVT), pulmonary emboli (PE), ileus, atelectasis, and pneumonia are some of the most common post-operative complications that can arise from prolonged immobility (Tevis \& Kennedy, 2013). Ambulating improves circulation and oxygenation, as well as muscular function and gastrointestinal motility. In addition, early ambulation is associated with decreased length of stay and a decrease in 30-day readmission rates (Kibler et al., 2012).

Patient ambulation is a very important nurse driven intervention. Nurses have been recognized as the most capable when implementing patient ambulation in the 
hospital when compared to other patient care providers (Doherty-King \& Bowers, 2017). However, in certain circumstances ambulation is overlooked and not done by some nurses. In some instances, ambulation is prohibited unless cleared by a provider's order. Doherty-King and Bowers (2017), found in their study nurses did not ambulate their patients unless there were clear physician orders to do so. Some patients are ordered strict bedrest following a particular procedure or need a physical therapy evaluation to be cleared prior to ambulation. This can cause confusion among nurses as to when it is ok to begin mobilizing a patient leading to longer immobility. Other reasons for the lack of patient ambulation were lack of time, role responsibility, and knowledge deficit (Cheifetz et al., 2010).

The purpose of this quality improvement project is to improve nursing knowledge regarding early ambulation after surgery for the prevention of post-operative complications. 


\section{Literature Review}

A comprehensive literature review was conducted utilizing CINAHL, PubMed, and Google Scholar as search engines. Literature was reviewed from the year 2000 to 2019. Key words used to search the databases included postoperative care, postoperative recovery, early ambulation, bed rest, complications to immobility, barriers to immobility, and nursing knowledge.

\section{Early Mobility}

Bedrest had been regarded as the fundamental treatment for tissue healing right up until the twentieth century (Spellman, 2000). It has also been frequently prescribed for some particular disease states such as the critically ill or post-cardiac catheterization (Brower, 2009). However, with advances in medical science and research immobility and bed rest have been identified as a contributing factor in the delay of a patient's recovery (Spellman, 2000). Complications can potentially pose cardiovascular, respiratory, renal, integumentary, gastrointestinal, and psychological risk to an ill patient (Brower, 2009).

In a systematic review by Brower (2009), the author analyzed several pieces of literature concerning potential benefits of increased bed rest as well as complications of immobility. Data collected from 8 randomized, control trials evaluated complications of bed rest and placed them into 8 categories: skeletal muscle atrophy and weakness, joint contractures, thromboembolic disease, insulin resistance, microvascular dysfunction, systemic inflammation, atelectasis, and pressure ulcers. Researchers measured potential beneficial effects of bed rest including immediate post-procedural treatment and primary preventative treatment of post-operative complications. The results revealed that although 
there are some possible benefits to bed rest, clinical studies did not support its use for the potential harm outweighed the benefit (Brower, 2009).

\section{Post-Operative Complications}

Surgical procedures involve direct insult and injury to the human body. Given the invasive nature of surgery, postoperative complications are not uncommon. The number of surgical procedures performed nationwide in 2019 alone exceeded 50 million and as many as $30 \%$ of these surgical patients experienced some sort of postoperative complication (Mehta et al., 2019). The risk of complications varies with each individual patient and surgical procedure. Postoperative complications indicate a significant alteration in the course of a patient's recovery and can not only prolong length of stay but also significantly increase a patient's morbidity and mortality. Complications can include cardiovascular, respiratory, gastrointestinal, renal, integumentary, and psychological. Although not all complications can be prevented, some can be completely avoided. Prevention of complications is important to a patient's hospital course and overall recovery (Mehta et al., 2019).

Cardiovascular Complications. The potential effects that immobility may have on the cardiovascular system include decreased contractility or cardiac function, increased heart rate, venous thromboembolism, dehydration, and orthostatic hypotension. Lucca (2020) conducted an integrative review on early ambulation's effects on the cardiovascular complications four hours post-femoral PCI (percutaneous coronary intervention). The main purpose of this study was to assess if nurses felt that the optimal ambulation time of four hours post PCI had any influence on vascular complications in these patients. The results indicated that low-risk patients are eligible for early ambulation at four hours or 
less post-femoral access PCI and nurses should consider a patient's history and risk factors prior to ambulating the patient (Lucca, 2020). The study showed the importance of the nursing role in increasing comfort while decreasing discomfort and complications for those patients who have undergone femoral access PCI. However, it did reveal that there was not enough clinical evidence that connects the risk factors and early ambulation.

According to Santos et al. (2017), the heart rate at rest will increase one beat per minute for every two days of immobility. This results in the heart being less capable of responding to the demand above its original baseline due to the decreased diastolic filling and shorter systolic ejection. Furthermore, decreased diastole results in decreased coronary blood flow and a smaller amount of available oxygen needed for myocardial nutrition (Santos et al., (2017).

Venous thromboembolism (VTE) is another complication of prolonged immobility and bedrest after surgery. Virchow's triad discusses the pathophysiologic mechanisms in which the development of a VTE is possible. Virchow's triad explains three factors in which a person may be predisposed thromboembolism formation. The three factors are hypercoagulability, venous stasis, and endothelial injury (Guedes et al., 2018). Remaining still for long periods of time inhibits normal muscle contraction and blood circulation, particularly of the calf musculature. This leads to pooling of blood in the lower extremities, which inhibits adequate systemic circulation. Blood flow then becomes sluggish causing venous stasis. Furthermore, both pooling of blood and venous stasis of the lower extremities reduces the amount of clotting factors cleared by the liver which then increases blood viscosity. Finally, when a person remains in the supine 
position it creates increased stress and damage to the underlying endothelium. Therefore, collagen is exposed creating a medium for platelets to aggregate and stick thus forming clots (Chatterly, 2017).

A retrospective cohort study by Assareh et al (2016) reviewed all VTE cases amongst hospital admissions from 2002-2009. During this period, it was found that over 380,000 admissions were surgical in nature. Of those surgical admissions, one in ten developed a VTE. When compared to non-surgical admissions, surgical patients were 28\% more likely to develop a VTE. (Assareh et al., 2016).

Respiratory Complications. Post-operative respiratory complications occur in up to $23 \%$ of patients 48-72 hours following surgery. Risk factors for the development of respiratory complications include age, pre-existing medical conditions, smoking, surgery, and immobility (Miskovic \& Lumb, 2017). Changes to the respiratory system occur immediately on anesthesia induction in which both the respiratory drive as well as muscle function are altered. Functional capacity is weakened, the diaphragm is displaced leading to postoperative atelectasis and pneumonia (Rao \& Khanna, 2018). With continued immobility or being supine for a prolonged period of time, patients are unable to take an effective breath because of decreased tidal volume and restricted ribcage movement (Chatterly, 2017).

Gastrointestinal Complications. Prolonged immobility can also negatively effect the gastrointestinal (GI) tract. One of the most common GI complications following a surgical procedure is an ileus. An ileus is defined as the reduction or absence of GI function after a surgical procedure or after periods of prolonged immobility (Volpi et al., 2016). It is further characterized by increased nausea and/or vomiting, accumulation of 
fluids or gas in the bowel, decreased or absent bowel sounds, the delayed passage of flatus and stools, and abdominal distention. Each portion of the GI tract assumes normal function at different times following surgery. However, during the postoperative period patients can remain immobile and less active which can extend the duration in which bowel function returns. Interruption in the return of bowel function can delay resumption of oral intake and increase infections processes (Volpi et al., 2016).

Renal Complications. Two of the most common renal complications associated with immobility are the formation of renal calculi and urinary tract infections (Guedes et al., 2018). When assuming the supine position for a long period of time, the kidneys are unable to properly drain urine from the kidneys to the bladder. Drainage of urine through the urinary calices is impaired therefore increasing the time the urine can precipitate causing crystalloids and calculi. Furthermore, this increased precipitation time can lead to stasis of urine in the kidneys and bladder. This allows for bacterial growth, which can lead to urinary tract infections. In addition to urinary tract infections and renal calculi, patients can also be at risk for developing urinary incontinence. While supine, residual urine accumulates in the bladder making it difficult for patients to void, especially in this position. The bladder can become distended weakening the detrusor muscle causing urinary incontinence. (Guedes et al., 2018).

Integumentary Complications. Immobility after surgery puts a patient at risk for impaired skin integrity and breakdown due to the reduction in blood circulation. A disruption in tissue circulation can further lead to impaired surgical wound healing and tissue perfusion. It is estimated that greater than $90 \%$ of all pressure injuries occur on the sacrum, ankle, heel, ischial tuberosity, and the greater trochanter. Once prolonged 
pressure is exerted to the skin for prolonged periods of time circulation is impaired. This produces increased heat, pressure, and reduced oxygenation, which impedes the generation of new cells and further increases the risk of skin breakdown (Guedes et al., 2018). Immobility reduces the blood circulation and so reduces wound perfusion.

Psychological Complications. Prolonged immobility can have a devastating psychological impact on patients. Combined with immobility, being in the hospital for an extended period of time and social isolation can lead to anxiety, confusion, insomnia, irritability, and most importantly delirium (Rudolph \& Marcantonio, 2012). Delirium is especially prevalent in the older adult population. Patients experiencing delirium after surgery recover significantly slower than those without delirium. Delirium can continue for months after postoperative onset and is associated with poor cognitive and functional outcomes. Risk factors for the development of delirium include medication administration, preexisting physiological or physical illness, increasing age, surgical procedure, and immobilization (Rudolph \& Marcantonio, 2012).

\section{Enhanced Recovery After Surgery}

Enhanced recovery after surgery (ERAS) is an evidenced based and patient centered multidisciplinary approach aimed at maintaining preoperative organ function and to reduce the stress response patient's may have following their procedures (AANA, 2019). ERAS protocols do not just begin in the hospital; they are integrated from home to preadmission, preoperative, intraoperative, postoperative and post discharge phases of the surgical process (Melnyk et al., 2011).

Introduced in the 1900's by United Kingdom Professor Henrik Kehlet, ERAS protocols, also known as fast-track programs, had become a principal focus in the 
perioperative management of surgical patients (AANA, 2019). The prehospital phase of any ERAS protocol begins with patient and family education followed by the preoperative phase. This phase focuses on nutrition, pain management discussions, and discharge planning. The intraoperative phase focuses on hemodynamic monitoring, opioid sparing multimodal analgesia, and the avoidance of drains and tubes. Early mobilization and further patient education are the main focus of the immediate postoperative phase. Early mobilization supports patients return to baseline functional status, reduces the need for analgesia, and aids in the return of bowel and bladder function. The final component of the ERAS protocol is the post-discharge phase. This phase emphasizes the importance of follow-up care, continued therapy if needed, and the monitoring of any adverse signs and symptoms (Melnyk et al., 2011).

Research has consistently shown that adapting an ERAS protocol leads to a substantial improvement in reduction of healthcare cost, patient outcomes, and patient satisfaction. It is important to note that in order for any ERAS protocol to be effective and successful, a collaborative and multidisciplinary approach combined with staff education is invaluable (AANA, 2019).

In a prospective cohort study performed by Stethen et al. (2018), investigators focused on the effects that an ERAS protocol had on postsurgical ambulation, length of stay, patient recovery and outcomes. They examined how their ERAS protocol improved patient outcomes in abdominal surgery in 127 patients from January 1, 2014 through December 1, 2016. A low-cost ambulation team was created who were responsible for making sure that patient ambulation goals of three times per day were met. These ambulation technicians had no formal training like the physical therapist, nurses, and 
physician assistants but were educated on patient safety, fall prevention, and proper lifting techniques. Any patient with ambulation restrictions was seen by the physical therapy team. The results demonstrated an association between failures to ambulate with longer length of stays. Additionally, there was a correlation between a refusal to ambulate with those that developed a complication. Stethen et al., (2018) found a significant correlation $(\mathrm{p}=<0.001,64.2 \%)$ between ambulated patients and decreased post-operative complications, narcotic pain control, and length of stay. Continued improvement in patient outcomes with a post-operative protocol leads to a focus on the patient's participation, a reduction in narcotic use, and early identification of high-risk patients (Stethen et al., 2018).

\section{Benefits of Early Mobilization After Surgery}

One of the earliest documented references discussing postoperative activity can be traced back to Dr. Kim Canavarro in World War II (Canavarro, 1946). In 1946, Dr. Canavarro piloted a program that changed the recommendations of postoperative ambulation. Prior to the initiation of the program, postoperative ambulation began on or after postoperative day 10. Complications included pneumonia, atelectasis, venous thromboembolism, urinary catheterization, abdominal distention requiring decompression, and one death from a pulmonary embolism all occurring after postoperative day 3. After reviewing and analyzing data from 401 surgical cases, Canavarro determined that the probability of a marked reduction in postoperative complications with early ambulation was 267.2 to 1 . Canavarro concluded that there was a significant decrease in the rate of postoperative complications among those who ambulated postoperative day 1 compared to patients that began ambulation at or after day 
10. He also stated that postoperative day 1-2 "is the optimum time to ambulate patients since most of the complications occur in the early postoperative period" (Canavarro, 1946, p180).

In the last 15 years, many health systems across the globe have implemented many, if not all, of the ERAS concepts with significant improvement in surgical outcomes (AANA, 2019). In an ambispective cohort review Owoicho et al. (2017) aimed to examine the effects early mobilization had not only on complication reduction but also patient outcomes, length of hospital stay, and readmission rates.

Owoicho et al. (2017) performed a retrospective analysis on prospectively collected data on 125 patients aged 65 and older who underwent elective spinal surgery for the correction of adult degenerative scoliosis. The authors divided patients into two groups: early ambulators and late ambulators. Early ambulators $(\mathrm{n}=66)$ were those patients who began ambulation within the first 24 hours after surgery while the late ambulators $(\mathrm{n}=59)$ began ambulation 48 hours or more postop. Postoperative complications were measured as well as postoperative functional status, length of stay, and 30-day readmission rate (Owoicho et al., 2017).

The researchers found that patients who were ambulatory within the first 24 hours following surgery exhibited a lower incidence or postoperative complications, shorter length of stay, and improved functional status at the time of discharge. Unexpectedly, researchers also found that the early ambulatory cohort (72\%) was more likely to be discharged home instead of a rehabilitation facility when compared to the late ambulatory cohort (22\%). It was concluded that when ambulation was started immediately (within the first 24 hours after surgery) there was a reduction in the prevalence of postoperative 
complications (54.3\%), and length of hospital stay (4.2 days vs 6.9 days), as well as an improvement in functional status and a decreased need for discharge to a rehabilitation facility. The investigators also noted that their findings suggested a higher complication rate with poor patient outcomes when ambulation was started after 24 hours (Owoicho et al., 2017).

\section{Barriers to Early Ambulation}

Nurses play an integral role in the ambulation of any patient admitted to the hospital and as a result have a direct impact on the outcomes of those patients. Nurses have also been recognized as the healthcare provider most capable of promoting ambulation simply because they have the most direct patient contact (Sepulveda-Pacsi et al., 2016). In having such contact with the patients, it enables the nurses to be acutely aware of the overall physical and functional condition of the patients and their capability of safely ambulating. However, some nurses report deferring the decision making on whether or not to ambulate patients to a physician or physical therapist (Sepulveda-Pacsi et al., 2016).

Reeve et al. (2019) conducted a study with the aim of determining the physiotherapy management of patients undergoing upper and lower abdominal surgery performed via open or laparoscopic approaches in public hospital surgical units throughout New Zealand. The study used a purposed survey that was administered to twenty three $(\mathrm{n}=23)$ physiotherapists in public hospitals. With a response rate of $19 \%$, none of the respondents reported routine physiotherapy input prior to the surgery. The study included only one surgical center that provided the rehabilitation pre-operatively to high risk patients. The physiotherapists reported post-operative assessments and 
treatments were routinely performed after open upper abdominal surgery. The study then concluded that physiotherapy interventions for patients receiving abdominal surgery mainly focus on the postoperative assessment and treatment of patients undergoing abdominal surgery in New Zealand. This study aids in the understanding the impacts of the rehabilitative and postoperative assessments and the paths to recovery. Furthermore, it offers a clear insight on the differences existing in rehabilitative and postoperative assessments of the patients.

An exploratory, cross sectional study performed by Sepulveda-Pacsi et al., (2016) examined 192 RNs working on a post-surgical unit in Northern Manhattan Hospital. A modified version of the Missed Nursing Care Survey (MISSCARE) was utilized to collect data. In terms of the importance of ambulation, data from the survey revealed that the majority of nurses felt that frequent and early ambulation was extremely important to a postoperative patient's recovery and complication prevention (72\%) while others felt ambulation was important to the patient's hospital stay (27\%), and only a very small number of nurses felt it was not important at all (1\%). Furthermore, the primary barriers to patient ambulation were listed as an inadequate number of clinical staff, both nursing and clerical staff, urgent patient situations that require a great deal of patient care time, rises in patient volume, increased patient acuity, and lack of knowledge on importance of patient ambulation (Sepulveda-Pacsi, et al., 2016).

Sawyers (2019) conducted a literature review on the barriers of early ambulation. The survey examined the benefits of early ambulation and barriers in the process of implementing early ambulation. The study selected seven articles that were peer reviewed. From the study, it was found that early ambulation leads to shorter stays in the 
hospitals, lower costs from the hospitals, as well as fewer post-operative complications. However, it identified lack of nursing education as the major barrier in the implementation of the early ambulation. Therefore, the study recommended that nurses must educate the patients on the benefits of early ambulation. Nurses should also collaborate with other health professionals to ensure that there is achievement of the goals in the early ambulation. Implementing the ambulation protocols must also be done in tandem with other health professionals. Rolling out ambulation protocols remains critical in ensuring that the barriers are eliminated in the process.

In a systematic review by Wainwright and Burgess (2020), the authors found that the barriers to early ambulation ranged from postoperative pain in patients, lack of patient motivation, inadequate staffing and a lack of ambulation culture. The study also discussed that in the future preoperative characterization may facilitate individualized and optimal patient care and help in reducing poor functional outcomes. Therefore, it is necessary to provide a qualitative understanding of the barriers to early ambulation in the hospitals and healthcare systems. Poor functional outcomes have the potential of affecting the patients and influencing the operations of the patients.

In a literature review by Dubb et al. (2016), researchers studied barriers to early ambulation and procedures to overcome them. The majority of barriers identified in the study were directly related to the patient, more specifically hemodynamic instability. Additionally, Dubb et al. identified several structural barriers impacting post-operative patient mobility. These barriers included limited patient care equipment, staff, staff education, and the absence of any ambulation protocol (Dubb et al, 2016). Furthermore, a 
lack of staff morale and general education in the importance of early mobility was identified.

The researchers also discussed barriers as it related to processes of care. These barriers included lack of planning, coordination, unclear staff expectations, and patient expectations. Dubb et al. (2016) identified ways to overcome these barriers which included patient centered and staff centered strategies. Frequent pain assessment, ambulation encouragement, specific patient centered goals, and including the patient in the plan of care were all identified as key strategies to enhancing patient participation. Lastly, Dubb et al. (2016) identified the single most important strategy as staff education. Without proper education staff, which includes nurses, nursing assistants, physical therapists, and providers, patients have unclear expectations about ambulating and can suffer from the lack thereof. To decrease the incidence of ambulation barriers, communication, collaboration, and staff education among all health care providers is key (Dubb et al, 2016).

Chatterly (2017) conducted a study on improving nurse knowledge and attitudes of early mobilization of the post-operative patient. In this study, Chatterly (2017) administered pre-survey, educational session, and post-surveys to twenty-five nurses. From the study, post-survey scores increased by $16.8 \%$ and the knowledge was improved. Time and pain were identified as the major barriers to the early mobilization of the patients (Chatterly, 2017). The study showed the importance of knowledge-based questions on assessing the performance of nurses. Furthermore, this study concluded that improving nurses' knowledge surrounding the benefits of early mobilization is critical in the management of pain in postoperative patients. 
When a patient is admitted to the hospital for any reason, there are orders related to patient activity. These activity orders can range from strict bed rest to ambulation as tolerated, which in turn helps nurses plan patient care. Based on the all the literature reviewed, there is clear evidence to support that early ambulation after surgery decreases the rate of post-operative complications, shortens duration of admission, and improves the patient's overall functional status after surgery. Yet despite this evidence, gaps remain in adherence to post-operative ambulation and nursing knowledge. Early ambulation of the postoperative patient has a positive impact not only on the individual's functional status but also significantly reduces the likelihood of complications after surgery. Although barriers do exist in practice, it is curial to support nursing by providing educational models that discuss the importance of early ambulation and benefits therein. The purpose of this quality improvement project is to improve nursing knowledge regarding early ambulation after surgery for the prevention of post-operative complications.

The following theoretical frameworks used to guide this quality improvement project will be discussed. 


\section{Theoretical Frameworks}

The theoretical frameworks chosen for the development of this project are Lewin's Theory of Change and the Logic Model.

\section{Lewin's Change Theory}

Lewin's Change Theory was developed by German social psychologist Kurt Lewin in the 1950's. This theory is based on three stages of change described by Lewin as unfreezing, change, and refreezing. It requires previous knowledge and learning be ignored and replaced with new learned behaviors through planned change. The concept of planned change happens intentionally because of a newly learned behavior instead of a change that is spontaneous or that occurs by coincidence (McEwen \& Wills, 2019). The idea of unfreezing is the means in which one forgoes the use of an old way of doing things that did not seem to be beneficial or productive. The change stage involves the moving to a new way of doing things, whether it be through actions, thoughts, feelings, or a combination of the three. Finally, the refreezing stage occurs when the change is formed into a new routine or habit so much so that it becomes regular practice.

Refreezing is a crucial step in this process and without adherence it can essentially be easy for the old ways to be reintroduced (Burnes, 2020).

Lewin's theory is centered on three concepts that are essential for change: driving forces, restraining forces, and equilibrium. Lewin states that if both driving and restraining forces can be identified early on it is a good possibility that change will be successful (McEwen \& Wills, 2019). Driving forces push or assist movement in a direction where change occurs (Petiprin, 2016). These forces enable change because they drive or push in the preferred direction towards an anticipated outcome or goal. 
Restraining forces attempt to resist or push back the driving forces in the opposite direction away from the goal (McEwen \& Wills, 2019). Equilibrium is a state in which opposing forces are equal or balanced. In this theory, equilibrium is reached when the driving forces equal the restraining forces and there is no change. Equilibrium can increase or decrease depending on the forces at play. When implemented correctly, this theory has been shown to provide effective and lasting change (McEwen \& Wills, 2019).

Lewin's Change theory was used to evaluate the need for change, implement, and evaluate an educational intervention to evaluate nurses' knowledge of early ambulation and complication prevention. Lewin's Change Theory was an appropriate model for the current project as it will guide the development of a program for nurses on the importance and benefits of early ambulation in post-operative patients on the postsurgical nursing unit.

\section{Logic Model}

The Logic Model, was chosen to guide this quality improvement project for its systematic and visual representation of planning and systems approach towards a desired result (Mccawley, 2001). The Logic Model serves as a four step outline integrating planning, implementation, and evaluation of a program. This is further done through four basic components: resources, activities, outputs, and outcome (W.K. Kellogg, 2004). The inputs, or resources used for this project include what needs to be invested in this project such as staff participation, time, effort, administrative support, educator support, technology, equipment, and facilities. Outputs look at what is done and the people that are reached like providing products, pamphlets, and services to informed staff and decision makers. Defining what the outputs are allows the researcher to form a clear link 
between the situation and the outcomes. The project outcomes can be then divided into short, intermediate, and long-term. The Logic Model further utilizes the SMART method for outcomes and their impacts. Outcomes should be specific, measurable, action oriented, realistic, and timed. Utilizing all components of the Logic Model and the Logic Model Development Guide, a guide was created in order to demonstrate the educational plan and intervention for this project. (W.K Kellogg, 2004)

Next, the methods will be discussed. 


\section{Purpose}

\section{Methods}

The purpose of this quality improvement project is to improve nursing knowledge regarding early ambulation after surgery for the prevention of post-operative complications.

\section{Design}

The quality improvement project utilized a pre-test, educational intervention, post-test design. The evidenced-based educational session served as the intervention.

\section{Site}

This project was conducted on two 11-bed surgical units located in a 160-bed teaching hospital in Rhode Island. This inpatient unit cares for general, bariatric, oncologic, and neuro-spine surgical patients.

\section{Sample}

The participants were 17 of 22 staffed part-time and full-time registered nurses from the 2 inpatient surgical units from all shifts. Excluded from this sample were float and per-diem nurses.

\section{Procedures}

Application of the Logic Model. The components of the Logic Model framework were used to guide this quality improvement project (W.K. Kellogg, 2004). These components included situation, inputs, outputs, and impact.

Situation. For this quality improvement project, the situation was measuring nursing knowledge of early ambulation of the postoperative patient and complications prevention on two inpatient surgical units. 
Inputs and outputs. Inputs are means that were needed and invested into project. Without inputs this project would not be achievable. Staff investment and time, managerial and administrative support, educational materials, technology, and time spent by the program developer are all crucial components of input. The outputs are population activities and participation. Activities in this quality improvement project included the pre and post tests and the educational intervention. The voluntary pre and post tests provided a critical understanding of various aspects that are vital in achieving the objective of this project. Evidence based literature and resources were used to create the educational intervention, which was delivered in person in the form of scheduled inservice power point presentations.

Outcomes. Outcomes are defined as the results or changes during and at the end of the quality improvement project. Outcomes are further subdivided into short, medium, and long-term. This quality improvement project focused on short-term outcomes, which aimed to measure nursing knowledge surrounding the benefits of postoperative ambulation and complication prevention. Additionally, by providing the educational inservice, nurses will gain a knowledge base, awareness, and a skill set as it pertains to the importance of postoperative ambulation and complication prevention. Medium term outcomes include behavior modification, informal observation of practice, and confidence to apply knowledge to nursing practice. Long term outcomes are characteristic of Lewin's Change Theory refreezing phase. These outcomes are changes in conditions or situations as the result of the intervention such as the reduction in postoperative complications as a result of continued and progressive postoperative ambulation. This project focused on the short-term outcomes only. 
Assumptions and external factors. The Logic Model includes assumptions and external factors. Assumptions are what needed to support the continuation of the quality improvement project. For this project, assumptions were comprised of the interest in participation of the nurses on the two surgical units in the pretest, educational session, and posttest. External factors are elements that can have a potential impact on the program's success. These factors included nursing willingness to participate, nursing availability for testing and educational sessions, administrative support, and resistance to change.

Program content and objectives. The main objective for this quality improvement project was to measure nursing knowledge about early postoperative ambulation and complication prevention. This objective was to be validated by improved posttest scores after the in-service educational intervention.

The educational intervention was created based on several factors. These factors included patient care survey responses, as well as in-depth conversations with surgical nurses, two clinical nurse educators, and an extensive literature review on the benefits of early postoperative ambulation.

\section{Procedures}

Permission and approvals. Prior to the execution of this project, approval was obtained from the IRB of both Rhode Island College and the hospital (Appendix A). Additional permission and approval from the Chief Nursing Officer and the surgical unit patient care director was granted prior to the start of the project. Additionally, feedback and approval of educational content, pre and posttests was sought and obtained by the surgical unit patient care director and the two clinical nurse educators of the hospital. 
All surgical nurses who were eligible to participate in the project were contacted and recruited by flyers and emails. Informational recruitment emails (Appendix B) were sent out approximately one month prior to the commencement of the project. At the same time, informational flyers (Appendix C) were posted in the nursing break room as well as floor news boards detailing session dates and times as well as contact information for the project developer. Educational sessions were delivered during shift hours for convince of participants and to encourage participation

Intervention. The educational in-service intervention was delivered in a lecturetype power point presentation. A copy of the lecture materials were provided to individual participants. The material included in the presentations incorporated evidencebased data and information gathered from the extensive literature review. Below the objectives and content are outlined in Table 1.

\begin{tabular}{l|l|}
$\begin{array}{l}\text { Table 1. } \\
\text { Program Content and Objectives }\end{array}$ & Program Objectives \\
\hline Program Content & $\begin{array}{l}\text { Able to define what ambulation is and } \\
\text { impact on postoperative patient care }\end{array}$ \\
\hline Introduction to ambulation & $\begin{array}{l}\text { Identify complications of immobility } \\
\text { following surgery }\end{array}$ \\
\hline Postoperative complications & $\begin{array}{l}\text { Identify benefits of early ambulation in } \\
\text { the postoperative patient on the surgical } \\
\text { unit }\end{array}$ \\
\hline $\begin{array}{l}\text { Importance of early postoperative } \\
\text { ambulation }\end{array}$ & $\begin{array}{l}\text { Discuss barriers and challenges to early } \\
\text { ambulation including but not limited to } \\
\text { perceived nursing and patient barriers }\end{array}$ \\
\hline Barriers to ambulation & $\begin{array}{l}\text { Discuss interventions necessary for } \\
\text { optimal patient outcomes and ways to } \\
\text { enact change }\end{array}$ \\
\hline $\begin{array}{l}\text { Interventions and patient care to promotion } \\
\text { postoperative ambulation }\end{array}$ & \\
\hline
\end{tabular}

A total of four educational in-service sessions held in the surgical unit breakrooms were conducted from January to March. A pretest was given prior to the educational 
program, which required 5 minutes to compete. Program content was presented over the course of 10 minutes in order to limit time and maximize staff availability. Completion of posttest took an additional 5 minutes following the intervention. Ample time was available for discussion and questions following the conclusion of the sessions. Participants were given the opportunity to attend while on shift which aided in increased staff involvement.

Identifiable information was not collected nor requested as part of this project and pre and post tests however, a unique identification number was used. It was requested of the participants to place a numeric identifier on both pretest and posttest solely for the purpose of aggregate data comparison. Once complete tests were placed into an envelope and sealed. Following the pretest was the educational in-service session. Finally, the posttest was administered utilizing the same individual unique identifier. Again, those tests were placed into an envelope once completed and sealed. All tests were kept safely and securely in the nursing supervisor's office until the completion of all sessions.

\section{Measurement.}

The desired outcome of this quality improvement project was to assess nurse's knowledge of early ambulation of the postoperative patient and complication prevention. The outcome of this project was evaluated based on the comparative results of the pre and posttests, which followed the educational in-service sessions. The pre and posttests contained a total of 10 questions developed by the researcher designed to address the purpose of this project. The test questions were reviewed by one clinical nurse specialist, two nurse educators, and one surgical clinical nurse manager to assess subject content and clarity of questions. 


\section{Data Analysis.}

The data collected from both pre and posttests (Appendix D) were analyzed utilizing descriptive statistics and analyzed by aggregate.

Next, the results will be presented. 


\section{Results}

Seventeen out of a possible 22 nurses $(\mathrm{N}=17,77 \%)$ participated in and completed the pretest, educational in-service, and posttest. The pretest and posttest were made up of 5 knowledge based multiple choice questions and 5 opinion-based statements utilizing a Likert scale to mark answers.

Results of the knowledge-based pretest and posttest scores are displayed below in Figure 1.

Figure 1.

Comparison of Knowledge-based Pre and Posttest Scores.

Pre and Post Test Scores

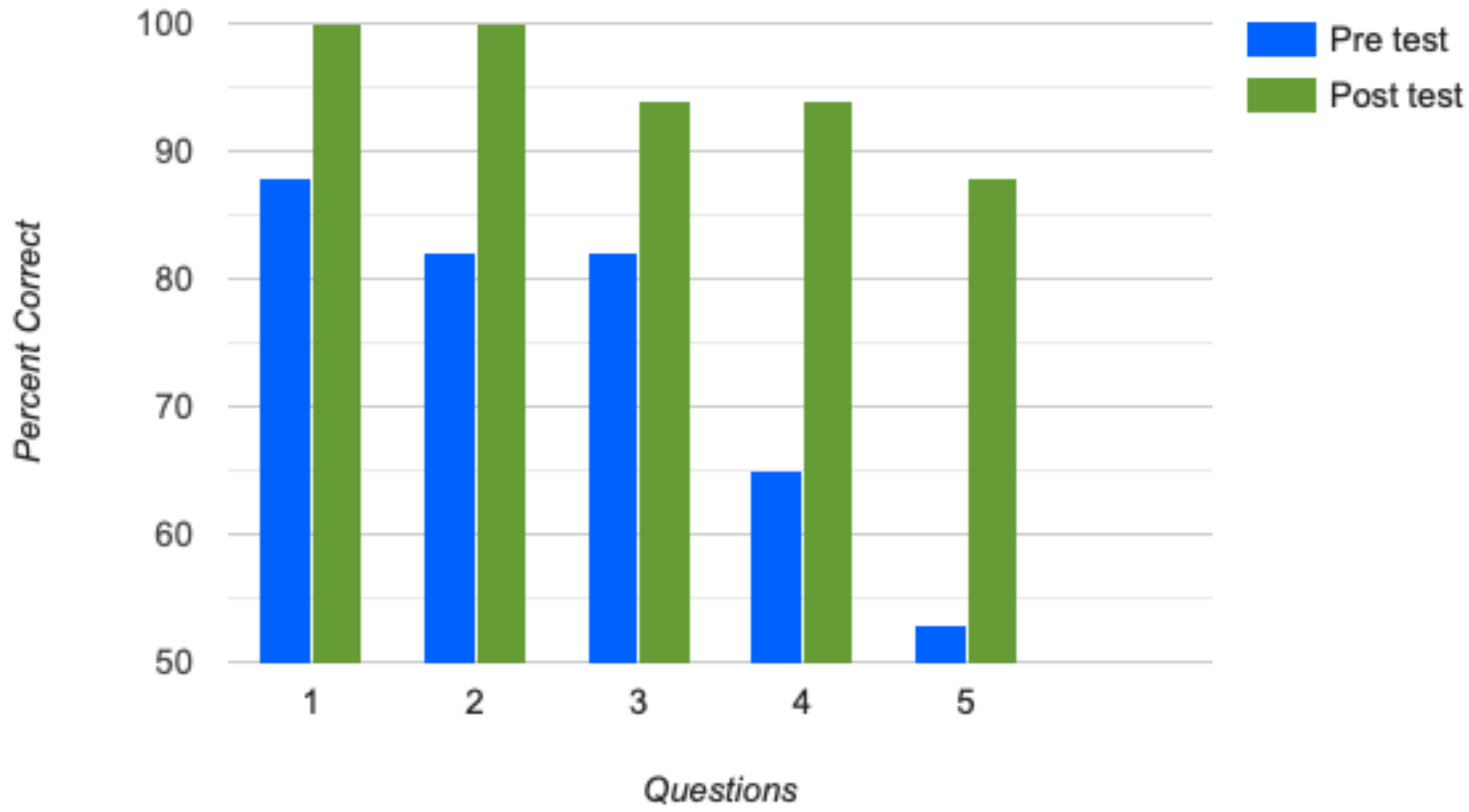

The scores ranged from $54 \%$ to $88 \%$ out of a possible $100 \%$ for the pretest with an average score of $74 \%$. The posttest scores ranged from $88 \%$ to $100 \%$ with an average score of $95 \%$. 
Individual knowledge-based questions are further broken down as displayed in Table 2.

Table 2.

Individual Knowledge-based Questions $(N=17)$

\begin{tabular}{|c|l|l|}
\hline Question & Pretest $(\mathrm{n}=17)$ & Posttest $(\mathrm{n}=17)$ \\
\hline 1 & $88 \%(15 / 17)$ & $100 \%(17 / 17)$ \\
\hline 2 & $82 \%(14 / 17)$ & $100 \%(17 / 17)$ \\
\hline 3 & $82 \%(14 / 17)$ & $100 \%(17 / 17)$ \\
\hline 4 & $65 \%(11 / 17)$ & $94 \%(16 / 17)$ \\
\hline 5 & $53 \%(9 / 17)$ & $88 \%(15 / 17)$ \\
\hline
\end{tabular}

Questions 1-5 were scored as correct or incorrect for the purposes of data comparison. These questions are available for review in Appendix D. Responses for questions 1-5 were used to determine the average test scores. Pre and posttest scores were analyzed for improvement following the educational in-service intervention. Individual correct scores for the knowledge-based pretest questions ranged from $53 \%$ to $88 \%$ with an average of $74 \%$. Posttest correct scores ranged from $88 \%$ to $100 \%$ with an average of $96 \%$. This demonstrates an improvement of $22 \%$ in overall scores.

Responses for questions six through ten were scored using a Likert scale. The responses were scored on a scale of 1 to 5 for purpose of data analysis. These numbers represented responses from 1-disagree, 2-somewhat disagree, 3-neither agree or disagree, 4-somewhat agree, and 5-agree. Mean scores were analyzed for each question and 
compared. In review of pretest question six, all of the participants somewhat agreed $(53 \%, \mathrm{n}=9)$ or agreed $(47 \%, \mathrm{n}=8)$ that ambulation is an important component of postoperative patient care. Posttest responses were similar however, more participants agreed $(76 \%, n=14)$ compared to somewhat agree $(24 \%, n=4)$. Question seven asked the opinion of the statement, "It is the responsibility of the physical therapist to ensure adequate patient ambulation." Responses ranged from disagree $(35 \%, \mathrm{n}=6)$, somewhat disagree $(29 \%, n=5)$, neither $(12 \%, n=2)$, and somewhat agree $(24 \%, n=4)$. Posttest responses indicated participants felt that it is not the responsibility of physical therapy to ensure adequate patient ambulation with $71 \%(\mathrm{n}=12)$ disagreeing and $29 \%(\mathrm{n}=5)$ somewhat disagreeing. Question eight asked if there is enough time during a shift to ensure adequate patient ambulation. Pretest responses ranged from disagree $(41 \%, n=7)$, somewhat disagree $(12 \%, n=2)$, somewhat agree $(18 \%, n=3)$, and agree $(29 \%, n=5)$. Posttest responses indicated 29\% $(\mathrm{n}=5)$ disagreed, $24 \%(\mathrm{n}=4), 12 \%(\mathrm{n}=2)$ somewhat agreed, and $35 \%(\mathrm{n}=6)$ agreed there was enough time during their shift to ensure adequate patient ambulation. This question showed the least improvement following the presentation with only a $6 \%$ increase in pre and posttest scores. Question nine asked the opinion of the statement, "Educating patients on the benefit of ambulation should be done." In the evaluation of pretest responses, the majority of participants felt that educating patients on the benefits of ambulation should be done with $94 \%(n=16)$ agreeing and $6 \%(\mathrm{n}=1)$ somewhat agreeing. Minimal change was noted in posttest responses with $100 \%(\mathrm{n}=17)$ agreeing that educating patients on the benefit of ambulation was a necessary component of patient care. Question ten assessed nurses' confidence in their ability to safely ambulate their postoperative patients. All participants who 
completed the pre and posttests either somewhat agreed or agreed in being confident. Pretest responses were 59\% $(\mathrm{n}=10)$ agreed and $41 \%(\mathrm{n}=7)$ somewhat agreed. Posttest responses indicated the majority agreed $(94 \%, \mathrm{n}=16)$ and one participant somewhat agreeing (6\%). Table 3 illustrates pretest responses whereas Table 4 illustrates posttest responses.

\section{Table 3.}

Pretest Opinion-Based Answers by Number of Participants (N=17)

\begin{tabular}{|l|l|l|l|l|l|}
\hline Questions* & Disagree & $\begin{array}{l}\text { Somewhat } \\
\text { Disagree }\end{array}$ & Neither & $\begin{array}{l}\text { Somewhat } \\
\text { Agree }\end{array}$ & Agree \\
\hline 6 & 0 & 0 & 0 & 9 & 8 \\
\hline 7 & 6 & 5 & 2 & 4 & 0 \\
\hline 8 & 7 & 2 & 0 & 3 & 5 \\
\hline 9 & 0 & 0 & 0 & 1 & 16 \\
\hline 10 & 0 & 0 & 0 & 7 & 10 \\
\hline *See appendix D for actual questions \\
\hline
\end{tabular}

Table 4.

Posttest Opinion-Based Answers by Number of Participants ( $N=17)$

\begin{tabular}{|l|l|l|l|l|l|}
\hline Questions* & Disagree & $\begin{array}{l}\text { Somewhat } \\
\text { Disagree }\end{array}$ & Neither & $\begin{array}{l}\text { Somewhat } \\
\text { Agree }\end{array}$ & Agree \\
\hline 6 & 0 & 0 & 0 & 4 & 13 \\
\hline 7 & 12 & 5 & 0 & 0 & 0 \\
\hline 8 & 5 & 4 & 0 & 2 & 6 \\
\hline 9 & 0 & 0 & 0 & 0 & 17 \\
\hline 10 & 0 & 0 & 0 & 1 & 16 \\
\hline *See appendix D for actual questions \\
\hline
\end{tabular}

The average scores of the four opinion-based questions were 4.5, 2.2, 2.8, 4.9, and 4.6. These pretest scores suggested that the some of the participants had a basic understanding of postoperative ambulation. The average scores for the posttest opinionbased questions were calculated and compared to the pretest averages. The mean scores 
were $4.7,1.6,3,5$, and 4.8 . respectively. The average scores increased with each question. The posttest results showed that the program objectives were met: nursing knowledge surrounding the importance of postoperative ambulation and complication prevention had increased. These results are displayed in Figure 2.

Figure 2.

Comparison of Knowledge-based Pre and Posttest Opinion-based Scores.

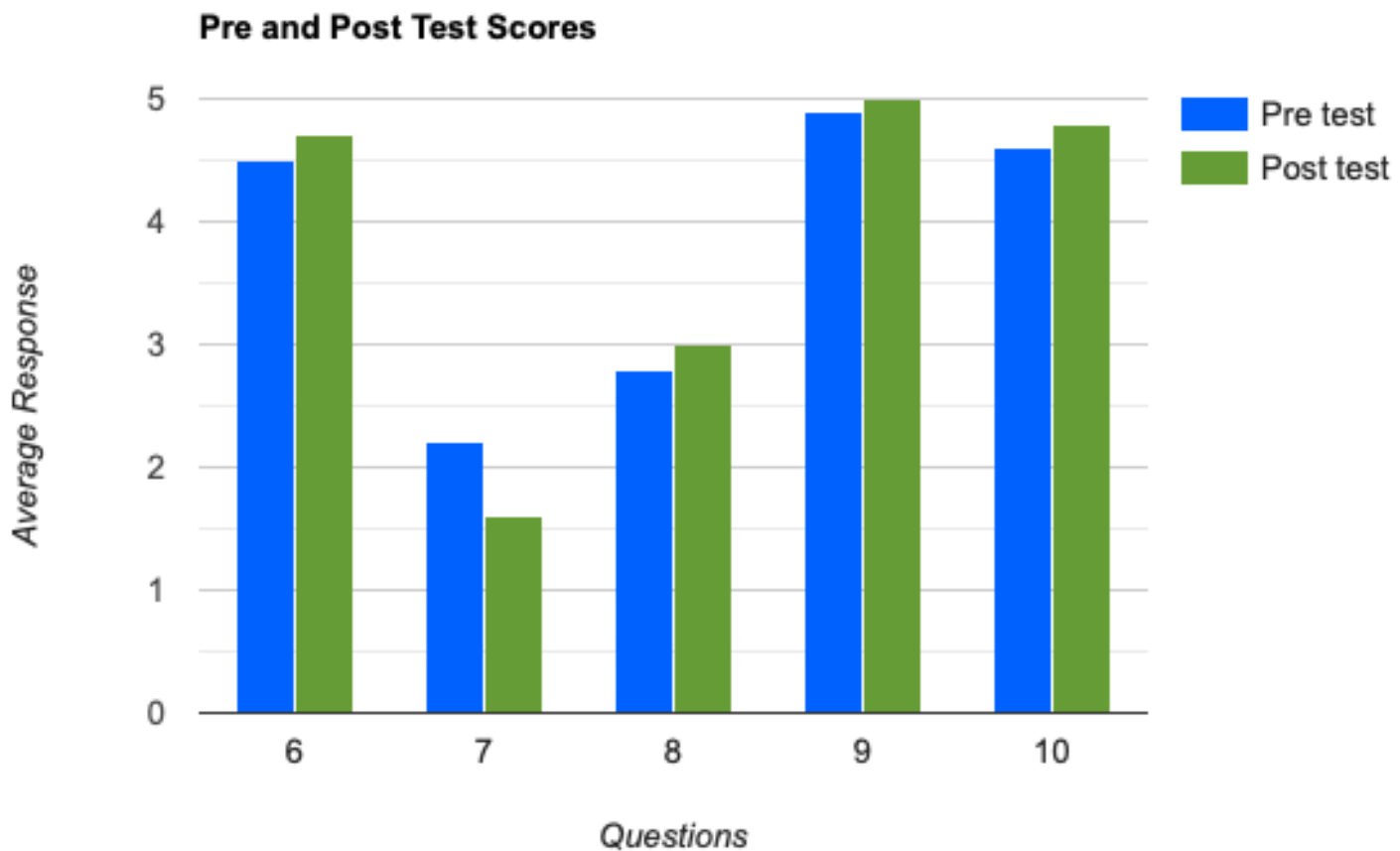

The scores ranged from 2.2 to 4.9 for the pretest. The posttest scores ranged from 1.6 to 5 . Both tests ranged from 1 to 5 .

Next the summary and conclusions will be discussed. 


\section{Summary and Conclusions}

The literature has revealed that early ambulation reduces the occurrence of complications in the postoperative patient. Today, early postoperative ambulation has become an essential component of postsurgical patient care and a critical part of exceptional nursing care delivery (Kibler et al., 2012). This quality improvement project was created due to observed inconsistencies with postoperative patient ambulation on the inpatient surgical units. Research has shown that when ambulation is started quickly following surgery the risk of complications decreases, as well as pain reduction and reduced length of stay (Chatterly, 2017).

A quality improvement project was created utilizing a pretest, educational inservice intervention, and posttest design which, was guided by both the Logic Model and Lewin's Theory of Change frameworks. These frameworks allowed this researcher to develop and deliver an evidence-based program in an attempt to increase the knowledge of surgical nurses. The purpose of this project was to improve nursing knowledge regarding early ambulation after surgery for the prevention of post-operative complications. The educational content presented to nurse participants included information obtained through extensive literature review. This content was presented on two surgical units in the form of a 10-minute Power Point presentation. Before execution of the project, approval was sought and obtained through both Rhode Island College and the individual hospital institutional review boards. Nursing staff was notified of the forthcoming educational in-service sessions from this researcher in the form of recruitment emails and flyers. Staff emails were initially sent out one month prior and flyers two weeks prior to the start date. Pretests were given before the educational in- 
service and posttests were administered following. Both pre and posttests responses were recorded and data was collected in an aggregate fashion. This data was used to assess for improved nursing knowledge regarding early ambulation after surgery for the prevention of post-operative complications

Seventeen out of 22 nurses (77\%) from the two hospital surgical units completed both the pretest, posttest, educational in-service intervention. Both pre and posttests were comprised of identical questions in identical formats. Each section of the tests was evaluated individually. All questions were created based on data and information gathered from the extensive literature review. Five out of 10 questions were knowledgebased, with scores increasing from an average pretest score of $74 \%$ to a posttest average score of $96 \%$. This demonstrated an improvement of $22 \%$ overall.

Questions 1-5 showed a marked increase in pretest and posttest scores following the educational intervention. Question one which asked about benefits of early ambulation, sought either a true or false response. Fifteen (88\%) participants were able to identify the correct answer in the pretest. In the posttest, $100 \%$ of participants answered correctly. Questions 2-5 were multiple choice. In question two, which asked about complications of immobility, 14 participants $(82 \%)$ were able to identify all the correct complications in the pretest. In the posttest, $100 \%$ of participants answered correctly. Question three was regarding barriers to postoperative ambulation. In the pretest, 14 (82\%) correctly answered. In the posttest, $100 \%$ of participants answered correctly. Question four was regarding the optimal time for postoperative ambulation. Eleven participants (65\%) identified the correct response in the pretest, while $16(94 \%)$ answered correctly in the posttest. Finally, question five was directed at the effects of early 
ambulation on postoperative pain control. In the pretest nine (53\%) participants answered correctly. In the posttest, fifteen (88\%) participants chose the correct answer. The increase from pretest and posttest shows that focused education in postoperative ambulation and complication prevention can help improve nurse's knowledge.

The additional 5 questions were opinion-based and measured on a 5 point Likert scale. Results of the pretest show that $47 \%(\mathrm{n}=8)$ believed that ambulation was an important component of post-operative patient care before participating in the educational in-service. Twenty-four percent $(n=4)$ somewhat agreed that it was the responsibility of physical therapy to ensure adequate patient ambulation while $35 \%(n=6)$ disagreed. When asked if they felt there was enough time during their shift to ensure adequate patient ambulation $29 \%(\mathrm{n}=5)$ of participants felt as though there was whereas $41 \%(\mathrm{n}=7)$ did not. The majority felt that educating patients on the benefits of ambulation should be done $94 \%(n=16)$. Fifty-nine percent $(n=10)$ of participants expressed confidence in knowing how to safely ambulate their patients after surgery. Following the educational in-service, the post test results indicated that $76 \%(\mathrm{n}=14)$ felt ambulation was an important component of postoperative patient care. Seventy-one percent of participants indicated it is not the responsibility of physical therapy to ensure adequate patient ambulation. When nurses were asked if there was enough time during their shift to ensure adequate patient ambulation $29 \%(\mathrm{n}=5)$ indicated there was not while $35 \%(\mathrm{n}=6)$ implied there was. This question showed the least improvement following the presentation with only a $6 \%$ increase in pre and posttest scores. A resounding $100 \%$ of participants felt that educating patients on the benefit of ambulation was a necessary component of patient 
care. Finally, $94 \%(n=16)$ expressed confidence in their ability to safely ambulate their postoperative patient.

There were some limitations identified in this quality improvement project. Nurses on the surgical units work in 12-hour shifts and educational sessions were scheduled accordingly. However, the times selected were not ideal for all 22 nurses, as sessions took place during work hours. Some participants were distracted by patient care needs, which increased the length of the in-services and effected the entire group.

The sample size was relatively small. There was a total of 22 full and part-time nurses who staffed both surgical units and were eligible to participate but only 17 joined in the project. The small sample size was due in part to individual time constraints, leave of absences, and floating off unit. The validity of the results from this project may be decreased given the small number of nurses who participated. Should a similar quality improvement project be replicated, it is recommended to include a larger group of participants to validate the positive results of this project.

Next, recommendations and implications for future practice will be discussed. 


\section{Recommendations and Implications for Advanced Practice Nursing}

Literature revealed that prolonged immobility has unfavorable outcomes for hospitalized patients. This is particularly true for all postoperative patients. The Advanced Practice Registered Nurse (APRN) plays a vital role in the prevention of unfavorable outcomes by utilizing their knowledge and expertise to guide practice. It is important that the nurse practitioner (NP) is up to date on the latest evidence and research and incorporate it into their daily practice. Additionally, the NP should serve as a leader and mentor by sharing their evidence-based practice knowledge to educate other advance practice providers and support bedside nurses.

In the advanced practice role, the NP can help in creating and implementing evidence-based educational programs. Not only would nursing benefit from this education surrounding early ambulation and complication prevention, but so would other patient care staff. The NP can also include physicians, certified nursing assistants, occupational, and physical therapists in their education. Doing so will foster interdisciplinary collaboration and dialogue surrounding early ambulation, potential barriers, and ways to increase compliance on the surgical units. Drolet et.al (2013) revealed that with the implementation of a customized nurse-driven early mobility protocol, there was a marked increase in ICU patient ambulation during the first 72 hours of hospital admission. APRNs are essential in serving as agents of change in the nursing practice.

The goal of this quality improvement project was to determine if nurse's knowledge of early ambulation and complication prevention of the postoperative patient would improve after an educational program. The significant improvement in post 
intervention scores following the educational in-service sessions validated the need for this program. While nurses spend about $61 \%$ of their time delivering direct patient care, educating nurses on the importance of early ambulation may allow them to integrate that knowledge into their daily practice (Butler et al, 2018). NPs play a pivotal role in this process by supporting nurse education and in turn improving patient outcomes. This project helped to recognize that there was in fact a need for ongoing education about postoperative ambulation for the surgical unit nurses. Educational programs about postoperative ambulation and complication prevention should be routinely incorporated in future trainings to ensure improved nursing knowledge. 


\section{References}

Adogwa, O., Elsamadicy, A. Fialkoff, J., Cheng, J.,Karikari, I., \& Bagley, C. (2017). Early ambulation decreases length of hospital stay, perioperative complications and improves functional outcomes in elderly patients undergoing surgery for correction of adult degenerative scoliosis. Spine, 42, 1420-1425.

https://doi.org/10.1097/BRS.0000000000002189

American Association of Nurse Anesthetists. (2019). Enhanced recovery after surgery. https://www.aana.com/practice/clinical-practice-resources/enhanced-recoveryafter-surgery

Assareh, H., Chen, J., Ou, L., Hillman, K., \& Flabouris, A. (2016). Incidences and variations of hospital acquired venous thromboembolism in Australian hospitals: A population-based study. BMC Health Services Research, 16(1), 511. https://doi.org/10.1186/s12913-016-1766-y

Bower, B. (2012). Managing change by empowering staff. Nursing Times. Retrieved from https:/www.nursingtimes.net/roles/nurse-managers/managing-change-byempowering-staff/5033731.article

Brower, R. G. (2009). Consequences of bed rest. Critical Care Medicine, 37, 422-S428. https://doi.org/10.1097/ccm.0b013e3181b6e30a

Brusko, G. D., Kolcun, J., Heger, J., Levi, A., Manzano, G., Madhavan, K., Urakov, T., Epstein, R., \& Wang, M. (2019). Reductions in length of stay, narcotics use, and pain following implementation of an enhanced recovery after surgery program for 1-to 3-level lumbar fusion surgery. Neurosurgical focus, 46(4), E4. http://doi.org/10/3171/2019.1.FOCUS18692. 
Burnes, B. (2020). The origins of Lewin's three-step model of change. The Journal of Applied Behavioral Science, 56(1), 32-59.

Butler, R., Monsalve, M., Thomas, G., Herman, T., Segre, A., Polgreen, P., \& Suneja, M. (2018). Estimating time physicians and other health care workers spend with patients in an intensive care unit using a sensor network. The American Journal of Medicine, 131(8), 972.e9-972.e15. https://doi.org/10.1016/j.amjmed.2018.03.015

Carbone, É., Takaki, M., Uyeda, M., \& Sartori, M. (2018). Early physical therapy intervention in gynecological surgery: "Case series". International Journal of Surgery Case Reports, 52, 95-102. https://doi.org/10.1016/j.ijscr.2018.09.051

Canavarro, K. (1946). Early postoperative ambulation. Annals of Surgery, 124(2), 180. Retrieved from: https://www.ncbi.nlm.nih.gov/pmc/articles/PMC1803619/

Chatterley, L. (2017). Improving nurse knowledge and attitudes of early mobilization of the postoperative patient. Retrieved from: https://digitalcommons.ric.edu/cgi/viewcontent.cgi?article=1190\&context=etd

Cheifetz O., Lucy S., Overend T., \& Crowe J. (2010). The effect of abdominal support on functional outcomes in patients following major abdominal surgery: a randomized controlled trial. Physiotherapy Canada, 62(3), 242-253. https://doiorg.ric.idm.oclc.org/10.3138/physio.62.3.242

Doherty-King, B., \& Bowers, B. (2017). Attributing the responsibility for ambulating patients: a qualitative study. International Journal of Nursing Studies, 50(9), 1240-1246. https://doi.org/10.1016/j.ijnurstu.2013.02.007 
Dos Santos, P., Ricci, N., Suster, E., Paisani, D., \& Chiavegato, L. (2017). Effects of early mobilization in patients after cardiac surgery: a systematic review. Physiotherapy, 103 (1), 1-12. doi:10.1016/j.physio.2016.08.003.

Drolet A., DeJuilio, P., Harkless, S., Henricks, S., Kamin, E., Leddy, J., Lloyd, C., Waters, S., \& Williams, M. (2013). Move to improve: The feasibility of using an early mobility protocol to increase ambulation in the intensive and intermediate care settings. Physical Therapy \& Rehabilitation Journal, 93(2), 197207. https://doi.org/10.2522/ptj.20110400

Dubb, R., Nydahl, P., Hermes, C., Schwabbauer, N., Toonstra, A., Parker, A., \& Needham, D. M. (2016). Barriers and strategies for early mobilization of patients in intensive care units. American Thoracic Society Journal, 13(5), 724-730.

Kibler, V., Hayes, R. M., Johnson, D. E., Anderson, L. W., Just, S. L., \& Wells, N. L. (2012). Early postoperative ambulation, back to basics. AJN American Journal of Nursing, 112(4), 63-69.

Leithauzer, D.J. (1949). Rational principals of early ambulation. The Journal of the International College of Surgeons. 12(3):368-374

Lohsiriway, V., Jitmungngan, R. (2019). Enhanced recovery after surgery in emergent colorectal surgery; Review of literature and current practice. World Journal of Gastrointestinal Surgery. 11(2): 41-52. http://doi.org/10.4240/wjgs.v11.i2.41.

Lucca, M. (2020). An integrative review of early ambulation's effects on vascular complications four hours post-femoral PCI. Nursing Masters Papers. 379. Retrieved from: https://openriver.winona.edu/nursingmasters/379 
Mayor, M. A., Khandhar, S. J., Chandy, J., \& Fernando, H. C. (2018). Implementing a thoracic enhanced recovery with ambulation after surgery program: key aspects and challenges. Journal of Thoracic Disease, 10(32), S3809-S3814. https://doi.org/10.21037/jtd.2018.10.106

McCawley, P. (2015). The logic model for program planning and evaluation. University of Idaho. Retrieved from: https://www.researchgate.net/publication/237568681_The_Logic_Model_for_Pro gram_Planning_and_Evaluation

McEwen, M., \& Wills, E. M. (2019). Theoretical basis for nursing (5 ${ }^{\text {th }}$ ed.). Philadelphia: Wolters Kluwer Health / Lippincott Williams \& Wilkins

Mehta, R., Merath, K., Farooq, A., Sahara, K., Tsilimigras, D., Ejaz, A., Hyer, J., Paredes, A., Dillhoff, M., Cloyd, J., \& Pawlik, T. (2019) U.S. News and World Report hospital ranking and surgical outcomes among patients undergoing surgery for cancer. Journal of Surgical Oncology. 120(8), 1327-1334. https://doi.org/10.1002/jso.25751.

Melnyk, M., Casey, R. G., Black, P., \& Koupparis, A. J. (2011). Enhanced recovery after surgery (ERAS) protocols: Time to change practice? Canadian Urological Association Journal, 5(5), 342-348. https://doi.org/10.5489/cuaj.11002

Miskovic, A., Lumb. B. (2017). Postoperative pulmonary complications. British Journal of Anesthesia, 118(3), 317-334. https://doi.org/10.1093/bja/aex002

Narang, S., Shukla, S., \& Shivsharan, P. (2018). A comparative study between conventional hernioplasty and laparoscopic assisted hernioplasty. Journal of Evolution of Medical and Dental Sciences, 7(17), 2114-2118. 
Owoicho, A., Elsamadicy, A., Fialkoff, J., Cheng, J., Karikari, I., \& Bagley, C. (2017) Early ambulation decreases length of hospital stay, perioperative complications, and improves functional outcomes in elderly patients undergoing surgery for correction of adult degenerative scoliosis. Spine, 42(18), 1420-1425.

Pashikanti, L., \& Von Ah, D. (2012). Impact of early mobilization protocol on the medical-surgical inpatient population. Clinical Nurse Specialist, 26(2), 87-94. https://doi.org/10.1097/nur.0b013e31824590e6

Petiprin, A. (2016). Lewin's change theory. Nursing Theory. Retrieved from: http://www.nursing-theory.org/theories-and-models/Lewin-Change-Theory.php

Polit, D. F., \& Beck, C. T. (2017). Nursing research: Generating and assessing evidence for nursing practice $\left(10^{\text {th }}\right.$ ed.) Philadelphia: Wolters Kluwer Health/Lippincott Williams \& Wilkins.

Rao, K. \& Khanna, A. (2018). Postoperative respiratory impairment is a real risk for our patients: The intensivist's perspective. Anesthesiology Research and Practice. https://doi.org/10.1155/2018/3215923

Reeve, J., Anderson, L., Raslan, Y., Grieve, C., Ford, J., \& Wilson, L. (2019). The physiotherapy management of patients undergoing abdominal surgery: A survey of current practice. New Zealand Journal of Physiotherapy, 47(2).

Rudolph, J. L., \& Marcantonio, E. R. (2011). Review articles: postoperative delirium: acute change with long-term implications. Anesthesia and Analgesia, 112(5), 1202-1211. https://doi.org/10.1213/ANE.0b013e3182147f6d

Spellman, N. (2000). Prevention of immobility complications through early rehabilitation. Rehabilitation of the Injured Combatant. 12, 741-743. 
Stethen, T. W., Ghazi, Y. A., Heidel, R. E., Daley, B. J., Barnes, L., Patterson, D., \& McLoughlin, J. M. (2018). Walking to recovery: the effects of missed ambulation events on postsurgical recovery after bowel resection. Journal of Gastrointestinal Oncology, 9(5), 953-961. https://doiorg.ric.idm.oclc.org/10.21037/jgo.2017.11.05

Sawyers, A. M. (2019). Benefits of early ambulation: A literature review. [Capstone Project, Northern Illinois University]. University of Illinois Digital Archive. http://commons.lib.niu.edu/bitstream/handle/10843/21669/NURS\%20499\%20Capstone $\% 20$ Paper.pdf? sequence $=2 \&$ isAllowed $=y$

Sepulveda-Pacsi, L., Soderman, M., Kertez, L. (2016). Nurses' perceptions of their knowledge and barriers to ambulating hospitalized patients in acute settings. Applied Nursing Research. 32, 117-121.

https://doi.org/10.1016/j.apnr.2016.06.001.

Tevis, S., \& Kennedy, G. (2013). Postoperative complications and implications on patient-centered outcomes. Journal of Surgical Research. 181(1), 106-113. https://doi.org/10.1016/j.jss.2013.01.032

Tezber, K., Aviles, C., Eller, M., Cochran, A., Iannitti, D., Vrochides, D., \& Mcclune, G. (2018). Implementing enhanced recovery after surgery (ERAS) program on a specialty nursing unit. The Journal of Nursing Administration,48(6), 303-309. https://doi:10.1097/nna.0000000000000619

Volpi, A., Ialongo, P., Panebianco, A., Lozito, R., Prestera, A., Laforgia, R., Punzo, C., \& Palasciano, N. (2016). Long lasting postoperative ileus after surgery for intestinal 
obstruction due to left preduodenal hernia (LPDH): A case report. Journal of Surgery. 37(6), 271-274. https://doi.org/10.11138/gchir/2016.37.6.271

Wainwright, T. W., \& Burgess, L. (2020). Early ambulation and physiotherapy after surgery. Springer, Cham. https://doi.org/10.1007/978-3-030-33443-7_23

W. K. Kellogg Foundation. (2004). W.K. Kellogg foundation logic model development guide. Retrieved from: https://www.wkkf.org/resourcedirectory/resource/2006/02/wk-kellogg-foundation-logic-model-developmentguide.

Wojciechowski, E., Pearsall, T., Murphy, P., French, E. (2106). A case review: Integrating Lewin's theory with Lean's system approach for change. The Online Journal of Issues in Nursing. 21(2), 14-18.

Zhen, L., Xinmei, Z., Jing, C., Zheng, L., Xia, W., Jiaqian, L., Jing, J., Ge, L., Ying, L., Fanggang, L.,Baoyun, S., Jingfen, J., Yilan, L., Xianxiu, W., Shouzhen, C., Xinjuan, W. (2018). Nurses' knowledge and attitudes regarding major immobility complications among bedridden patients: A prospective multicenter study. The Journal of Clinical Nursing. 27, 1969-1980. https://doiorg.ric.idm.oclc.org/10.1111/jocn.14339. 
Appendix A

\section{RIC IRB Approval Letter}

From: "NoReply@TOPAZTI.net" <NoReply@TOPAZTI.net>

Date: December 30, 2020 at 9:57:27 AM EST

To: "Hodne, Melinda" < mhodne@ric.edu>, Institutional Review Board - Rhode Island College

$<$ irb@ric.edu>

Subject: IRB: \#2021-2133 (Hodne, Melinda) approved

Greetings,

The proposal for the project referenced below has been APPROVED by the Institutional Review Board (IRB).

Project title: NURSE'S KNOWLEDGE OF EARLY AMBULATION OF THE POST OPERATIVE PATIENT AND COMPLICATION PREVENTION

Approval \#: 2021-2133

Type of review:

Proposal type: Original

Principle Investigator: Hodne, Melinda

Fees received:

Funding status:

Approval date: $12 / 30 / 2020$

Expiration date: $12 / 30 / 2025$

A request to renew this protocol must be received by $12 / 30 / 2025$.

Click here to access the protocol: https://ricprod.topazti.net/Elements?emailLink=11\%2c102\%2c124942

Your responsibilities as the Principal Investigator on this project are as follows:

1. You may implement only those materials and methods approved by the IRB. Changes to the protocol topic or methods, including the elimination of previously-approved methods, require prior approval.

2. If you are using signed consent materials, a PDF of the form(s) with the approval stamp will be uploaded to your protocol. You must use this copy with participants.

3. Unanticipated problems or adverse events must be reported within three (3) days of your knowledge of the event.

4. If you wish to continue the project beyond the expiration date, you must complete and submit a progress/final report within 30-days prior to the expiration date. If approval to continue the project is not finalized by the expiration date, you must discontinue all work pertaining to this protocol and wait until approval is given before resuming data collection.

5. You must keep all research data and consent documents within your possession in a secured location for at least three (3) years after the completion of the study, including publications or presentations of any reports.

Best Regards,

Emily Cook, Ph.D.

Professor

Chair, IRB

Rhode Island College

IRB@ric.edu 


\section{Roger Williams Medical Center IRB Approval Letter}

Roger

Williams

ब추

钴

בָุ
FWA 00005452

IORG 0000040

December 21, 2020

Meghan Carides, RN

Re: "Nurses Knowledge of Early Ambulation of the Post-operative Patient and Complication prevention: A Program Development Project"

Administrative Review Review Date: December 14, 2020

Item Reviewed:

- Completed Request for Discarded/Stored Human Biological Specimens For Research Form

Based on the information you provided in the form and 45 CFR 46.102 and 45CFR Parts 60 and 164 it has been determined that the above referenced project does not constitute research involving human subjects therefore IRB review is not required and HIPAA authorization is not required.

Please note that the Human Research Review Committee (IRB), prior to commencement, must review any change in your project's activities that may involve human subjects' research.

The Human Research Review Committee is in compliance with the requirements in Part 56, Subchapter D, Part 312 of the 21 Code of Federal Regulations published January 27, 1981.

CC: Karen Geremia, Director, Research Department 


\title{
Appendix B
}

\section{Informational Email}

December 28, 2020

\author{
Staff Email
}

Dear Center 4 and East 4 Nurses,

My name is Meghan Carides and I am a graduate student at Rhode Island College. A portion of the master's student curriculum requires that I complete a project. I have decided to create a quality improvement project for surgical nurses on the fourth floor.

You are being asked to participate in a quality improvement project titled Nurse's Knowledge of Early Ambulation of the Post-Operative Patient and Complication Prevention. The purpose of this project is to develop an evidence-based educational program for surgical nurses regarding the importance of post-operative ambulation and complication prevention.

All full time and part time nurses on both units are encouraged to participate however, participation is completely voluntary. Should you agree to take part, you will be asked to attend one of several 10-minute educational sessions as well as a 5-minute pretest and post-test. Sessions will begin Saturday, January 23, 2021

I sincerely appreciate you taking the time to read this email and consideration to participate in this program. Should any questions arise about this project I encourage you to contact myself at Mbingham_6370@email.ric.edu or 401-301-4949.

Sincerely,

Meghan Carides, BSN, RN

Mbingham_6370@email.ric.edu

Rhode Island College 


\section{Appendix C}

\section{Recruitment Flyer}
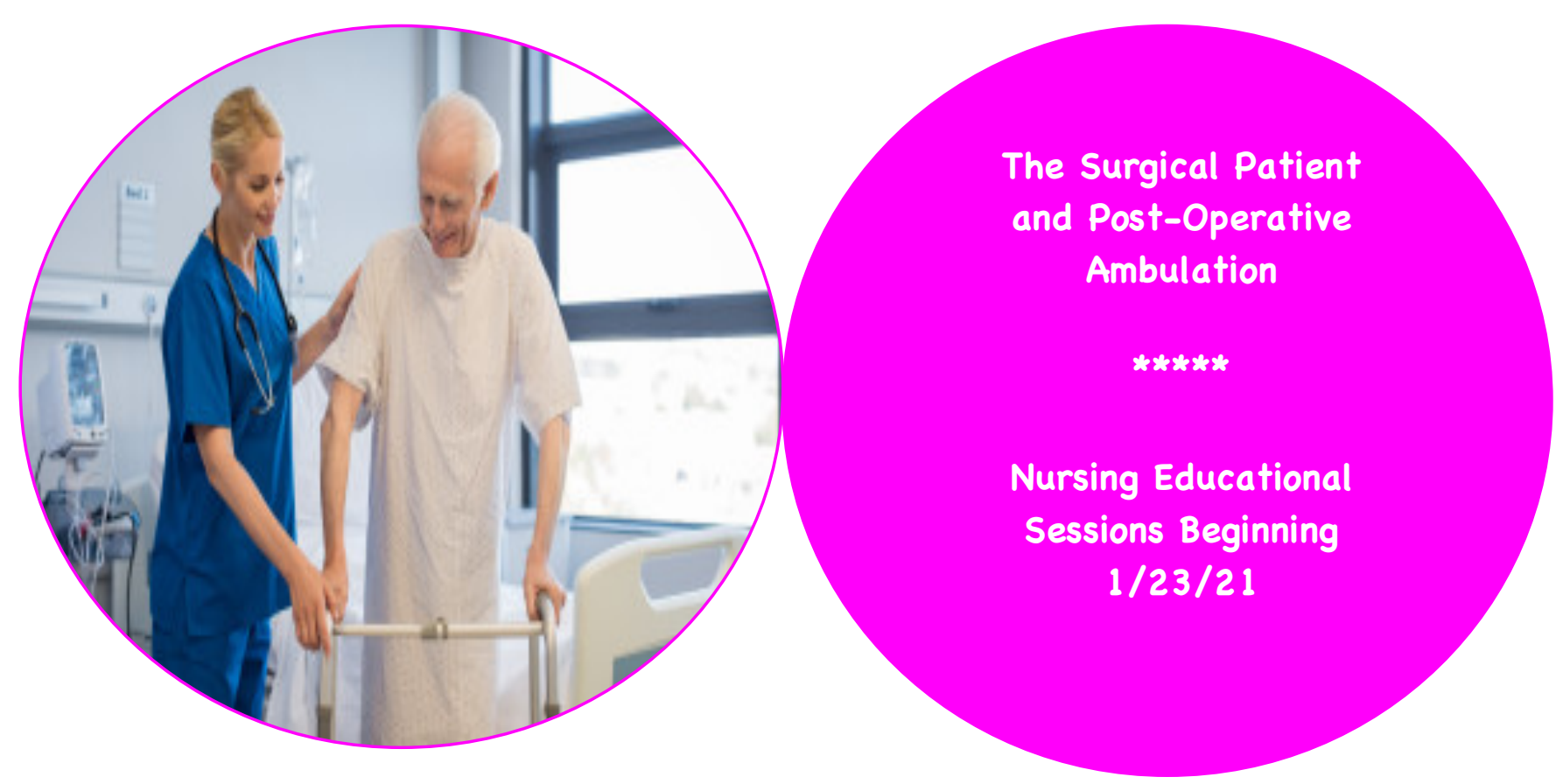

\section{ATTENTION ALL CENTER 4 AND EAST 4 NURSES!}

You are invited to participate in an education program about the importance of postoperative ambulation!

Improve your knowledge and confidence about ambulating surgical patients and discussing complication prevention!
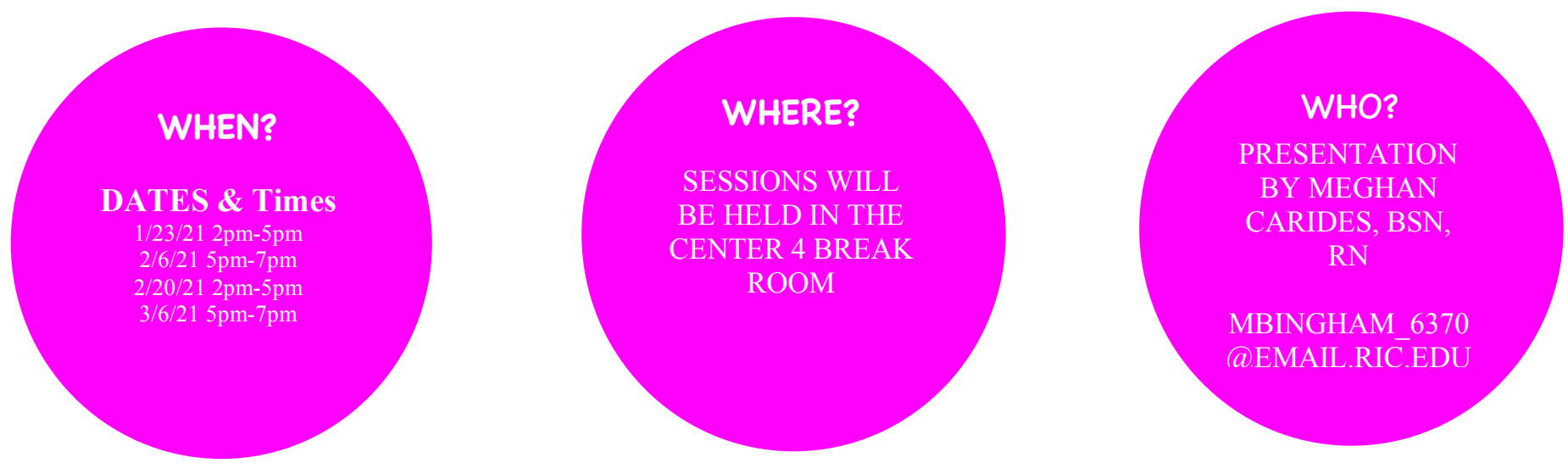


\section{Appendix D}

\section{Pre-Post Survey}

\section{Please circle the correct response.}

1. The benefits of early ambulation are only seen in the younger, healthier patient population.

a. True

b. False

2. Complication of immobility in the postoperative patient include:
a. Delirium
b. Atelectasis
c. Thromboembolism
d. Ileus
e. All of the above

3. Barriers to post-operative ambulation include all but which of the following:
a. High patient acuity
b. Patient refusal
c. Nursing refusal
d. Ventilated/Sedated patients

4. When is the optimal time to ambulate a patient following surgery?
a. Within 12 hours of surgery
b. POD \#3
c. 1 hour after surgery
d. Day of discharge

5. Research has shown that early ambulation has which effect on pain control after surgery?
a. Patients will require an increased amount of pain medication prior to ambulation
b. Ambulating patients will require an increased amount of pain medication after ambulation
c. There is no effect on pain management
d. Pain medication requirements to achieve satisfactory pain management will decrease




\section{Please circle the corresponding number based your opinion of the following} statements:

6. Ambulation is an important component of post-operative patient care

$\begin{array}{lllcc}1 & 2 & 3 & 4 & 5 \\ \text { Disagree } & \begin{array}{l}\text { Somewhat } \\ \text { disagree }\end{array} & \begin{array}{l}\text { Neither agree } \\ \text { or disagree }\end{array} & \begin{array}{l}\text { Somewhat } \\ \text { agree }\end{array} & \text { Agree }\end{array}$

7. It is the responsibility of the physical therapist to ensure adequate patient ambulation

$\begin{array}{lllcc}1 & 2 & 3 & 4 & 5 \\ \text { Disagree } & \begin{array}{l}\text { Somewhat } \\ \text { disagree }\end{array} & \begin{array}{l}\text { Neither agree } \\ \text { or disagree }\end{array} & \begin{array}{c}\text { Somewhat } \\ \text { agree }\end{array} & \text { Agree }\end{array}$

8. There is enough time during a shift to ensure adequate patient ambulation

$\begin{array}{lcccc}1 & 2 & 3 & 4 & 5 \\ \text { Disagree } & \begin{array}{c}\text { Somewhat } \\ \text { disagree }\end{array} & \begin{array}{c}\text { Neither agree } \\ \text { or disagree }\end{array} & \begin{array}{c}\text { Somewhat } \\ \text { agree }\end{array} & \text { Agree }\end{array}$

9. Educating patients on the benefit of ambulation should be done

$\begin{array}{lllcc}1 & 2 & 3 & 4 & 5 \\ \text { Disagree } & \begin{array}{l}\text { Somewhat } \\ \text { disagree }\end{array} & \begin{array}{l}\text { Neither agree } \\ \text { or disagree }\end{array} & \begin{array}{l}\text { Somewhat } \\ \text { agree }\end{array} & \text { Agree }\end{array}$

10. I am confident that I know how to safely ambulate my patient after surgery

\begin{tabular}{lllcc}
1 & 2 & 3 & 4 & 5 \\
\hline Disagree & $\begin{array}{l}\text { Somewhat } \\
\text { disagree }\end{array}$ & $\begin{array}{l}\text { Neither agree } \\
\text { or disagree }\end{array}$ & $\begin{array}{l}\text { Somewhat } \\
\text { agree }\end{array}$ & Agree
\end{tabular}

